\title{
The Testing Behind The Test Facility: The Acoustic Design of the NASA Glenn Research Center's World-Class Reverberant Acoustic Test Facility
}

The National Aeronautics and Space Administration (NASA) Glenn Research Center (GRC) is leading the design and build of the new world-class vibroacoustic test capabilities at the NASA GRC's Plum Brook Station in Sandusky, Ohio, USA. Benham Companies, LLC is currently constructing modal, base-shake sine and reverberant acoustic test facilities to support the future testing needs of NASA's space exploration program.

The large Reverberant Acoustic Test Facility (RATF) will be approximately 101,000 $\mathrm{ft}^{3}$ in volume and capable of achieving an empty chamber acoustic overall sound pressure level (OASPL) of $163 \mathrm{~dB}$. This combination of size and acoustic power is unprecedented amongst the world's known active reverberant acoustic test facilities. The key to achieving the expected acoustic test spectra for a range of many NASA space flight environments in the RATF is the knowledge gained from a series of ground acoustic tests. Data was obtained from several NASA-sponsored test programs, including testing performed at the National Research Council of Canada's acoustic test facility in Ottawa, Ontario, Canada, and at the Redstone Technical Test Center acoustic test facility in Huntsville, Alabama, USA. The majority of these tests were performed to characterize the acoustic performance of the modulators (noise generators) and representative horns that would be required to meet the desired spectra, as well as to evaluate possible supplemental gas jet noise sources. The knowledge obtained in each of these test programs enabled the design of the RATF sound generation system to confidently advance to its final acoustic design and subsequent on-going construction. 


\title{
The Testing Behind The Test Facility:
} The Acoustic Design of the NASA Glenn Research Center's World-Class Reverberant Acoustic Test Facility

\author{
Presented by: Aron D. Hozman \\ NASA Plum Brook Station, Sandusky, Ohio \\ Co-authors: William O. Hughes, Mark E. McNelis, \\ Anne M. McNelis \\ NASA Glenn Research Center, Cleveland, Ohio
}

IMAC XXIX, Jan.31- Feb.3, 2011 


\section{Introduction}

- The NASA Space Environmental Test (SET) Project is tasked to develop new test facilities, labeled as Vibroacoustic Test Capability (VTC), to support NASA's developing space exploration program.

- The Space Power Facility (SPF) located at the NASA Glenn Research Center's Plum Brook Station in Sandusky, OH, USA is already the home of the world's largest thermal vacuum chamber.

- In order to provide one-stop testing for the suite of space environmental testing, the SPF is being augmented through the NASA SET Project Office with new reverberant acoustic, mechanical vibration, and modal test facilities. 
Vibroacoustic Test Capability (VTC) Disassembly Bay Area Construction Photo (taken mid-December 2010)

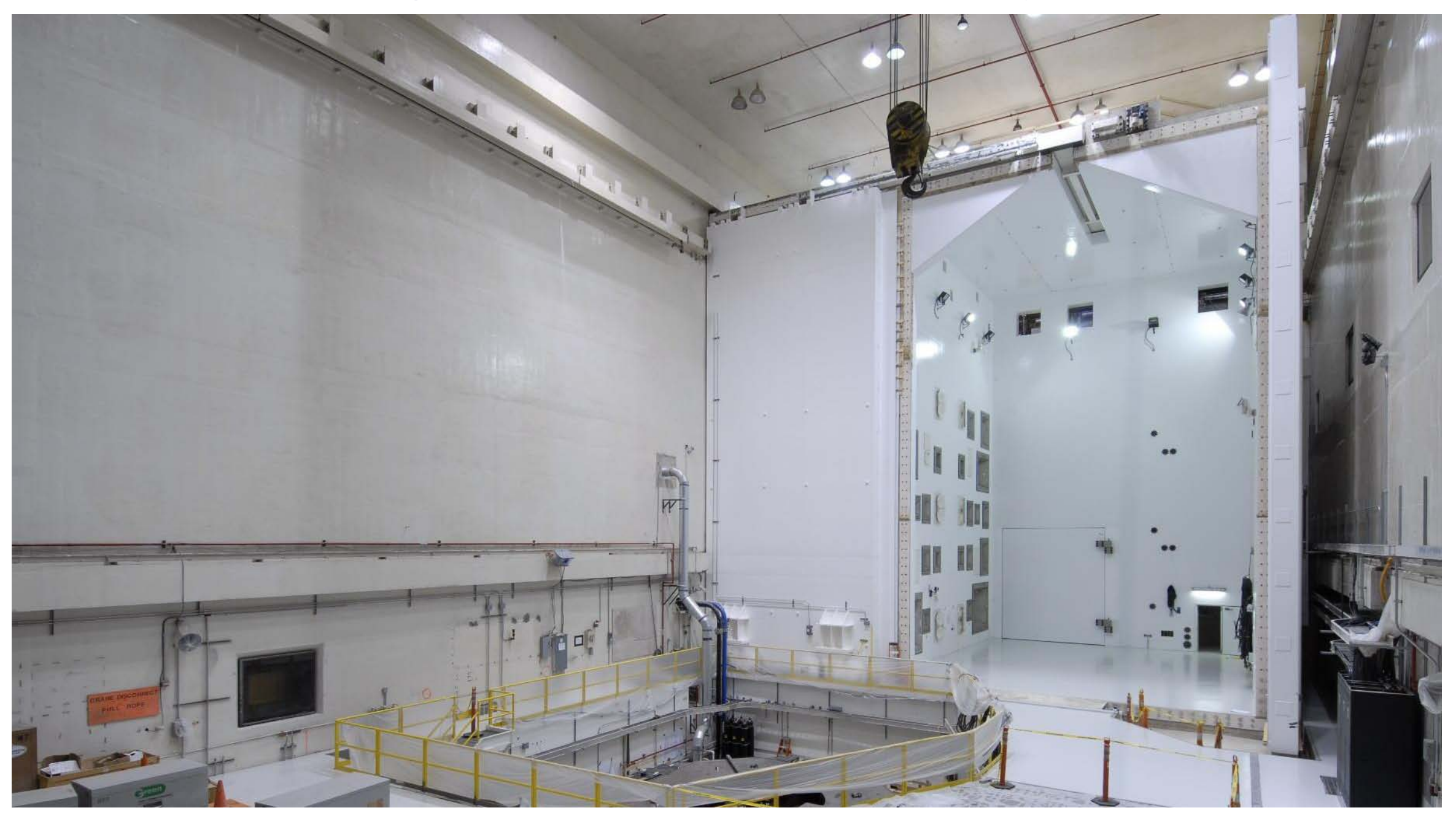




\section{Introduction (continued)}

- In August 2007, Benham Companies LLC, won the NASA prime contract to design and construct the acoustic, vibration and modal test facilities, as well as to provide the high speed data acquisition system to support these facilities.

- Benham contracted with Aiolos Engineering Corporation to provide the acoustic design of the Reverberant Acoustic Test Facility (RATF).

- This presentation addresses the various acoustic test programs that advanced the acoustic design of the RATF. 


\section{RATF Design Requirements}

- The RATF shall be as large as possible within the given space constraints of the SPF Disassembly Bay Area.

- The RATF's test chamber shall be properly sized to acoustically test four space vehicle configurations, encompassing an 18-ft diameter test article, and a 47-ft tall test article.

- The RATF's test chamber shall physically allow a 32.8-ft diameter test article weighing up to 120,000 pounds.

- The RATF shall generate the empty chamber acoustic test spectra shown in Figure 1, for continuous test duration of 10 minutes. These eight (8) "C" spectra represent a wide range of current and future NASA missions, including (5) spectra with a $163 \mathrm{~dB}$ overall sound pressure level (OASPL).

- The RATF acoustic control system shall control the noise sources in Fig. 1 within the following tolerances:

$> \pm 5 \mathrm{~dB}$ below the $50 \mathrm{~Hz}$ one-third octave bands(OTOB)

$> \pm 3 \mathrm{~dB}$ covering $50 \mathrm{~Hz}-2 \mathrm{KHz}$ OTOB's

$> \pm 5 \mathrm{~dB}$ above $2 \mathrm{KHz}$ OTOB's

$>1.5 \mathrm{~dB}$ on OASPL 
Figure 1. RATF Acoustic Test Spectral Design Requirements

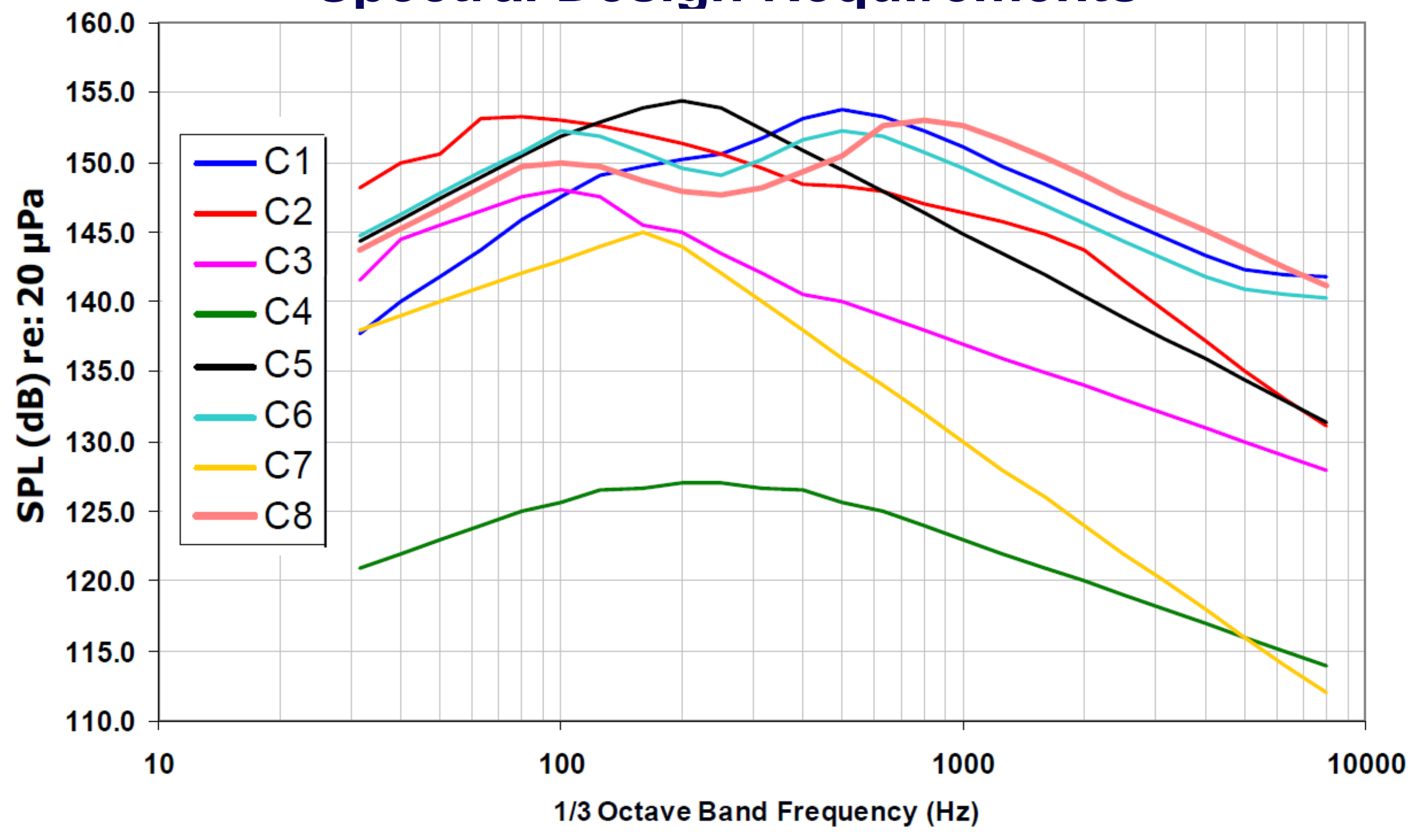




\section{RATF Chamber Sizing and Initial Acoustic Modulator Selection}

- Benham and Aiolos designed the reverberant acoustic test chamber with the following dimensions: 47.5-ft long $\times 37.5$-ft wide $\times 57-f t$ high.

The chamber volume is $\sim 101,000$ cubic $\mathrm{ft}$.

- $\quad$ The C2 test spectrum is particularly challenging due to its very high SPL at frequencies below $100 \mathrm{~Hz}$. This led Aiolos to initially select the TEAM Corporation (TEAM) modulators known as the MK-VI (150 kilowatts) and MK-VII (200 kilowatts) with low frequency (25, 35, and $50 \mathrm{~Hz}$ ) horns for the initial proposed RATF acoustic design.

- Although the TEAM modulators have been in service for over 50 years, there was not much acoustic characterization data available on them. To obtain characterization data, and to qualify and mitigate any associated risk, Aiolos, jointly with staff at the National Research Council of Canada (NRC) designed and conducted a test program at the Ottawa NRC reverberant acoustic test facility (chamber dimensions of $32-\mathrm{ft} L \times 22.6-\mathrm{ft} \mathrm{W} \times 26.3-\mathrm{ft} \mathrm{H}$, with a chamber volume of $\sim 19,000$ cubic $\mathrm{ft}$ ). 
Summary of Acoustic Tests Performed

\begin{tabular}{|c|c|c|c|}
\hline Test & Date & Location & Test Objective \\
\hline $\begin{array}{l}\text { NRC } \\
\text { I and II }\end{array}$ & $\begin{array}{l}\text { December } 2007 \\
\text { - January 2008, } \\
\text { April } 2008\end{array}$ & $\begin{array}{l}\text { NRC, Ottawa, } \\
\text { Ontario, Canada }\end{array}$ & $\begin{array}{l}\text { Acoustic response characterization of the } \\
\text { TEAM modulators and initial horn } \\
\text { evaluation. (Benham/Aiolos) }\end{array}$ \\
\hline Redstone & May 2008 & $\begin{array}{l}\text { Redstone Arsenal, } \\
\text { Huntsville, AL }\end{array}$ & $\begin{array}{l}\text { NASA independent acoustic } \\
\text { characterization of TEAM modulator and } \\
\text { horns, including high frequency horn. } \\
\text { Comparison of results with WAS } 3000 \\
\text { modulator. (NASA) }\end{array}$ \\
\hline Phase 1 & $\begin{array}{l}\text { March - April } \\
\quad 2009\end{array}$ & $\begin{array}{l}\text { NRC, Ottawa, } \\
\text { Ontario, Canada }\end{array}$ & $\begin{array}{l}\text { Jet testing. Additional TEAM modulator } \\
\text { acoustic characterization: } \\
\text { a. Modulator redesign acoustic response } \\
\text { b. Single modulator control } \\
\text { c. Dynamic range } \\
\text { (Benham/Aiolos) }\end{array}$ \\
\hline Phase 2 & October 2009 & $\begin{array}{l}\text { NRC, Ottawa, } \\
\text { Ontario, Canada }\end{array}$ & $\begin{array}{l}\text { Multiple modulator control. } \\
\text { WAS } 5000 \text { acoustic characterization. } \\
\text { (Benham/Aiolos) }\end{array}$ \\
\hline $\begin{array}{c}\text { Paint } \\
\text { Absorption }\end{array}$ & $\begin{array}{l}\text { February- } \\
\text { March } 2010\end{array}$ & $\begin{array}{l}\text { Owens-Corning, } \\
\text { Granville, OH }\end{array}$ & $\begin{array}{l}\text { Test characterization of acoustic absorption } \\
\text { of RATF wall paint. } \\
\text { (Cambridge Collaborative Inc. for NASA) }\end{array}$ \\
\hline
\end{tabular}




\section{Initial NRC Testing, Part 1 (directed by Aiolos)}

- Objectives:

a) Validate the acoustic performance and obtain operating parameters of the TEAM modulators.

b) Obtain acoustic test data to benchmark RATF's acoustic predictions.

- Key Findings:

a) The TEAM MK-VI and MK-VII modulators achieved their published acoustic power, performed well especially at low frequencies, and showed promise for meeting the RATF requirements.

b) The modulator's output varied linearly with input gain.

c) The modulator's bias setting (a measure of the force required to hold the modulator valve closed) requires further exploration to optimize its effect on noise generation.

d) Two modulator shaft failures occurred. 


\section{Initial NRC Testing, Part 2 (directed by Aiolos)}

- Objectives:

a) Examine quantitative relationship of shaft bias to modulator efficiency spectral control.

b) Utilize various spectral input signal shapes for open loop testing.

c) Instrument TEAM modulator shaft with strain gauges to provide data to assess previous shaft failures.

- Key Findings:

a) TEAM modulators were controllable from the $25 \mathrm{~Hz}$ to $500 \mathrm{~Hz}$ OTOB.

b) Optimal bias setting produced peak acoustic performance.

c) Demonstrated excellent repeatability in acoustic performance.

d) Performance between the $630 \mathrm{~Hz}$ to $800 \mathrm{~Hz}$ OTOB is due to nonlinear spillover and flow noise and subsequent gas flow problems.

e) Performance with the $200 \mathrm{~Hz}$ horn was poor due to inadequate connections.

f) One additional modulator shaft failure occurred. 


\section{Initial NRC Testing, Part 2 (directed by Aiolos)}

- Go-forward Plan:

a) TEAM Modulators controllability, repeatability and acoustic performance is sufficient for RATF design, especially at low to mid frequencies.

b) Shaft failures of TEAM modulators pointed to reliability issues and need to reanalyze and redesign shaft. 
- Objectives:

a) Obtain independent verification of the TEAM modulator acoustic performance (controllability, shape-ability, and repeatability) in the U.S. Army Redstone acoustic facility (chamber dimensions of $28.5-\mathrm{ft} L \mathrm{X}$ 24.3-ft W x 18.0-ft H, with a volume of $~ 12,500$ cubic $\mathrm{ft}$ ).

b) Collect data on two additional horn sizes (50 Hz and $167 \mathrm{~Hz}$ ).

c) Compare the responses of TEAM MK-VI modulators in the two facilities (Redstone and NRC).

d) Compare the response of the TEAM MK-VI and the Wyle Laboratories' WAS3000 modulators at the same facility (at Redstone).

- Key Findings:

a) Confirmed the NRC test findings of controllability, shape-ability and repeatability for the TEAM modulator.

b) TEAM modulator performed well with the $167 \mathrm{~Hz}$ horn.

c) Test data validated the analytical scaling procedures for using data in one chamber to predict the response in a different chamber.

d) Confirmed the NRC test findings of superposition of modulators' output. 


\section{Redstone Testing (directed by NASA)}

- $\quad$ Findings (continued):

e) The acoustic output of the MK-VI TEAM modulator was:

$>\quad$ Higher than that of the WAS3000 modulator by $6-7 \mathrm{~dB}$ at $25 \mathrm{~Hz}$ to $100 \mathrm{~Hz}$ OTOB

$>$ Similar from $125 \mathrm{~Hz}$ to $1000 \mathrm{~Hz}$ OTOB

$>\quad$ Higher by 2-3 dB from $1000 \mathrm{~Hz}$ to $8000 \mathrm{~Hz}$ OTOB due to non-linear spillover

f) Both the MK-VI and WAS3000 modulators allowed the generation of shaped spectra by controlling the input signal from $50 \mathrm{~Hz}$ to $630 \mathrm{~Hz}$.

- Go-forward Plan:

a) Pending a successful resolution of TEAM Modulator shaft failures, incorporate TEAM modulators into the RATF design.

b) In addition to the previously planned usage of low frequency horns, incorporate $160 \mathrm{~Hz}$ horn for RATF design. 


\section{Phase 1 Testing at NRC (directed by Aiolos)}

- Objectives:

a) Examine the acoustic performance of impinging gas jets, proposed as one alternative to meet the required high frequency spectra (for $\mathrm{C} 1, \mathrm{C} 6, \& \mathrm{C} 8$ ).

b) Reconfirm TEAM modulator's acoustic performance and life reliability with new shaft design.

c) Perform closed loop control of a single TEAM modulator.

d) Quantify the dynamic range of the TEAM modulator.

- Key Findings:

a) Gas jet testing showed that significantly more jets and accompanying gas flow than originally expected would be needed to satisfy RATF requirements.

b) Endurance testing of the TEAM modulator demonstrated that the shaft problem was resolved through the redesign. The measured stress levels on the shaft were greatly reduced and very close to the predicted levels by TEAM Corporation.

c) Testing also confirmed that the shaft redesign caused no significant change in the acoustic performance of the TEAM modulators. 


\section{Phase 1 Testing at NRC (directed by Aiolos)}

- Key Findings (continued):

d) Closed loop control testing of the TEAM modulator with the NRC control software was successful.

e) The dynamic range was found to be $\sim 6-9 \mathrm{~dB}$ for the $\mathrm{MK}-\mathrm{VI}$ and $\sim 9-12 \mathrm{~dB}$ for the MK-VII modulators.

- Go-forward Plan:

a) Incorporate TEAM modulators into RATF design.

b) To add robustness to the RATF design to handle future spectra, increase the number of horns types (i.e. incorporate several different horn cutoff frequencies for RATF design).

c) Gas jets are not to be utilized, but instead evaluate the proposal to incorporate the new Wyle product, the WAS5000 modulator (similar to the legacy Ling EPT-200 modulator), into the RATF design.

d) Aiolos to proceed with contract to select acoustic control system (ACS) for RATF and to demonstrate the ACS performance in the Phase 2 testing at NRC. 


\section{Phase 2 Testing at NRC (directed by Aiolos)}

- Objectives:

a) Characterize the Wyle Laboratories WAS5000 modulator acoustic performance in a similar manner as the TEAM modulator.

b) Demonstrate the operation of the $m+p$ International ACS, including the simultaneous closed loop control of the three modulators (TEAM MK VI and MK VII, Wyle WAS5000).

- Key Findings:

a) WAS5000 modulator's acoustic performance met or exceeded the expectations going into this test.

b) The $m+p$ ACS controlled the three modulators simultaneously meeting the specified test tolerances, stability and ramp-up rates.

- Go-forward Plan:

a) Incorporate the WAS5000 modulators on a $250 \mathrm{~Hz}$ horn into the RATF design.

b) Incorporate the $m+p$ ACS system into the RATF design. 


\section{Paint Absorption Testing at Owens-Corning (directed by Cambridge Collaborative Inc. for NASA)}

- Objectives:

a) Measure the acoustic absorption in the Owens-Corning reverberation chamber painted with the proposed RATF paint.

b) Compare results with expectations and absorption values used in Aiolos' SPL predictions for RATF.

- Key Findings:

a) Measured test data and subsequent decay rate analysis indicates that the selected paint for RATF has absorption characteristics consistent with expectations and with predicted analytical values used by Aiolos for their RATF acoustic predictions and design.

- Go-forward Plan:

a) Approve the paint selected by Benham for use in RATF chamber. 


\section{Conclusions}

- From the beginning, Benham, Aiolos and NASA have agreed that it was important to ground the acoustic predictions of the RATF chamber with actual test data given the extreme SPL required for RATF, and the lack of available performance data for the TEAM MK-VI and MK-VII and the Wyle WAS5000 acoustic modulators.

- Numerous and extensive test programs were completed to obtain the necessary test data to benchmark the RATF acoustic predictions. These test series have provided NASA with the confidence to proceed with the Benham and Aiolos design for RATF.

- The overall layout and key properties of the RATF chamber and horn room are illustrated in Figure 2 . There will be a total of 36 modulators and 36 horns to produce the acoustic power to meet the RATF requirements. The RATF design (see Figures 3, 4, and 5) has:

$>$ Eleven (11) MK-VII modulators distributed on the 25, 35, 50 and $80 \mathrm{~Hz}$ horns

$>$ Twelve (12) MK-VI modulators distributed on the 100 and $160 \mathrm{~Hz}$ horns

$>$ Thirteen (13) WAS5000 modulators on the $250 \mathrm{~Hz}$ horns 


\section{Figure 2. RATF Acoustic Design}

\begin{tabular}{|l|l|l|l|}
\hline & \multicolumn{1}{|c|}{ Chamber Properties } \\
\hline
\end{tabular}




\section{Figure 3. Modulator/Horn Pairings}
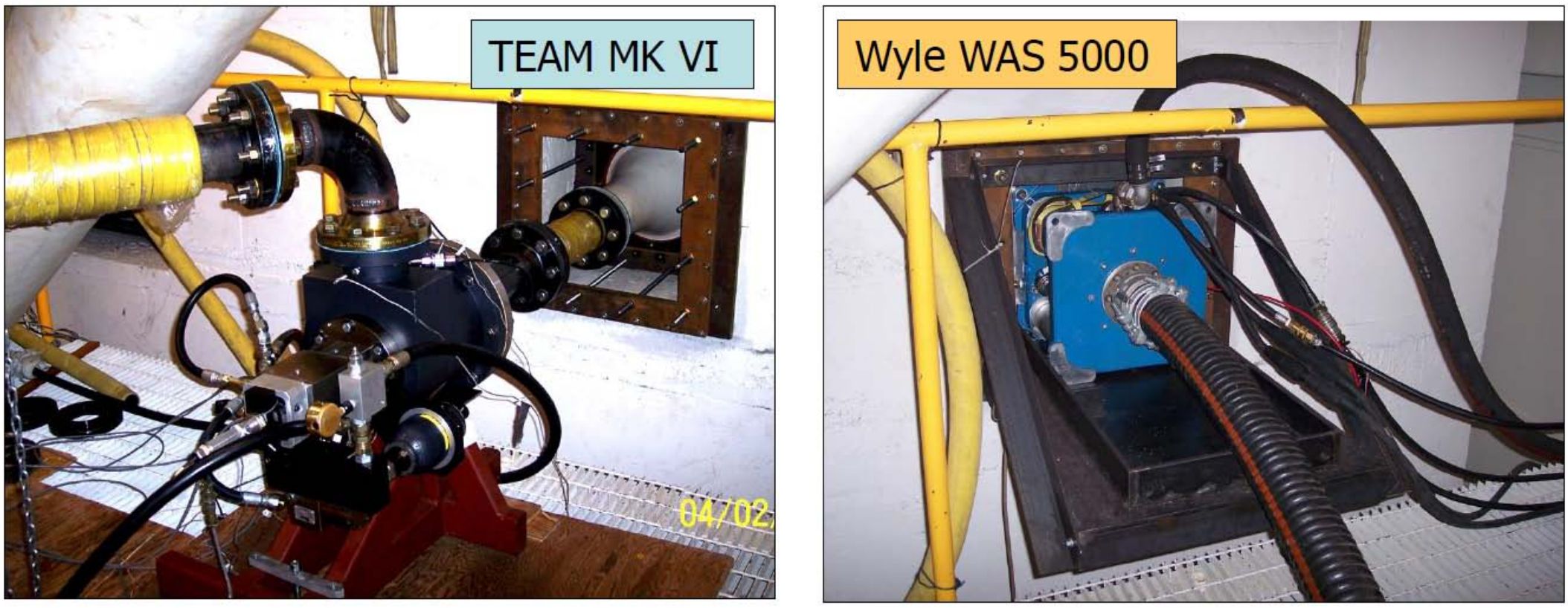

\begin{tabular}{|c|c|c|c|c|c|c|c|c|}
\hline Horn & $25 \mathrm{~Hz}$ & $35 \mathrm{~Hz}$ & $50 \mathrm{~Hz}$ & $80 \mathrm{~Hz}$ & $100 \mathrm{~Hz}$ & $160 \mathrm{~Hz}$ & $250 \mathrm{~Hz}$ & TOTAL \\
\hline Modulator & MKVII & MKVII & MKVII & MKVII & MKVI & MKVI & WAS5000 & \\
\hline $\begin{array}{c}\text { Final Design } \\
\text { Count }\end{array}$ & 2 & 2 & 4 & 3 & 4 & 8 & 13 & 36 \\
\hline
\end{tabular}

IMAC XXIX 
Figure 4. RATF Horn Layout

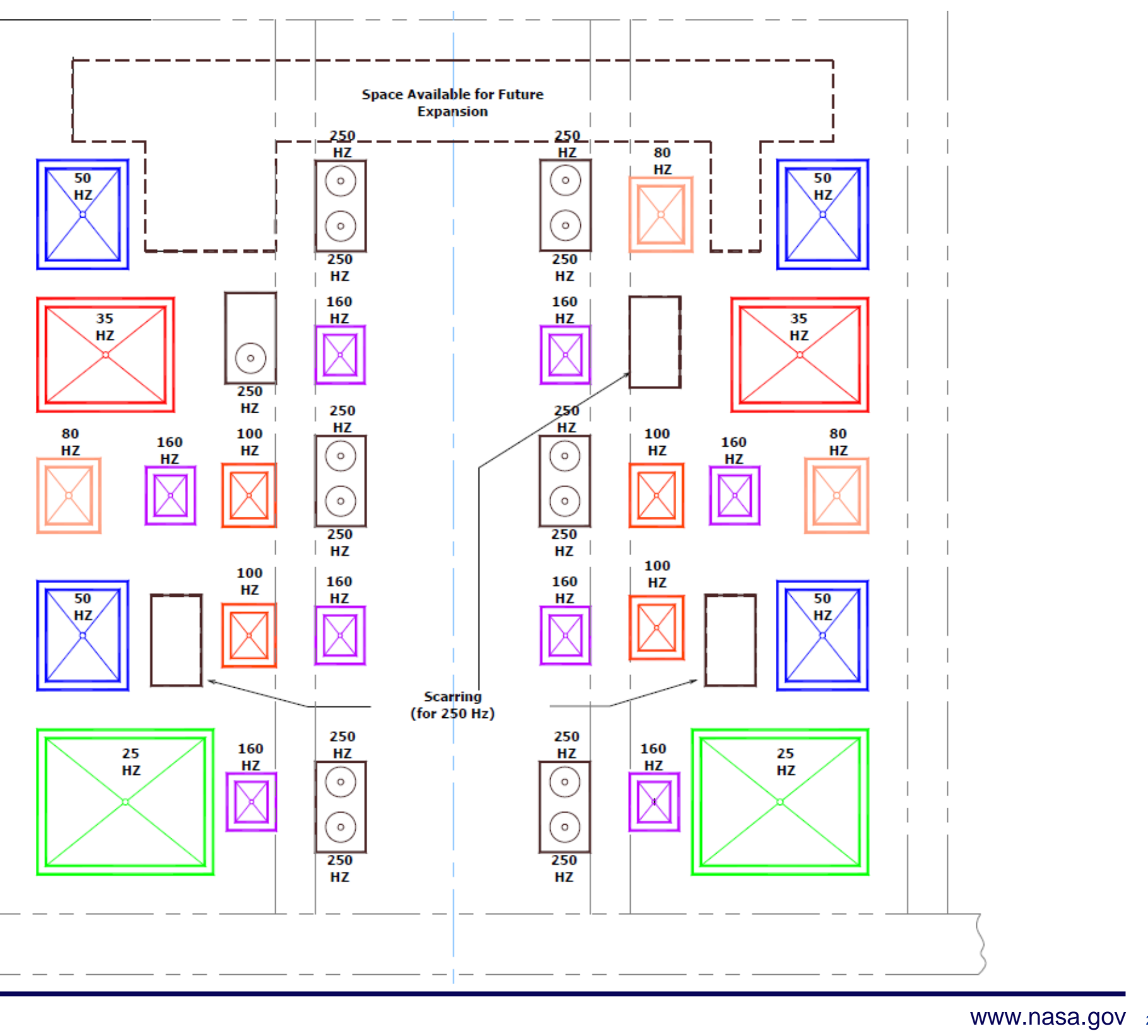


Figure 5. RATF Construction Photo (taken September 2010)

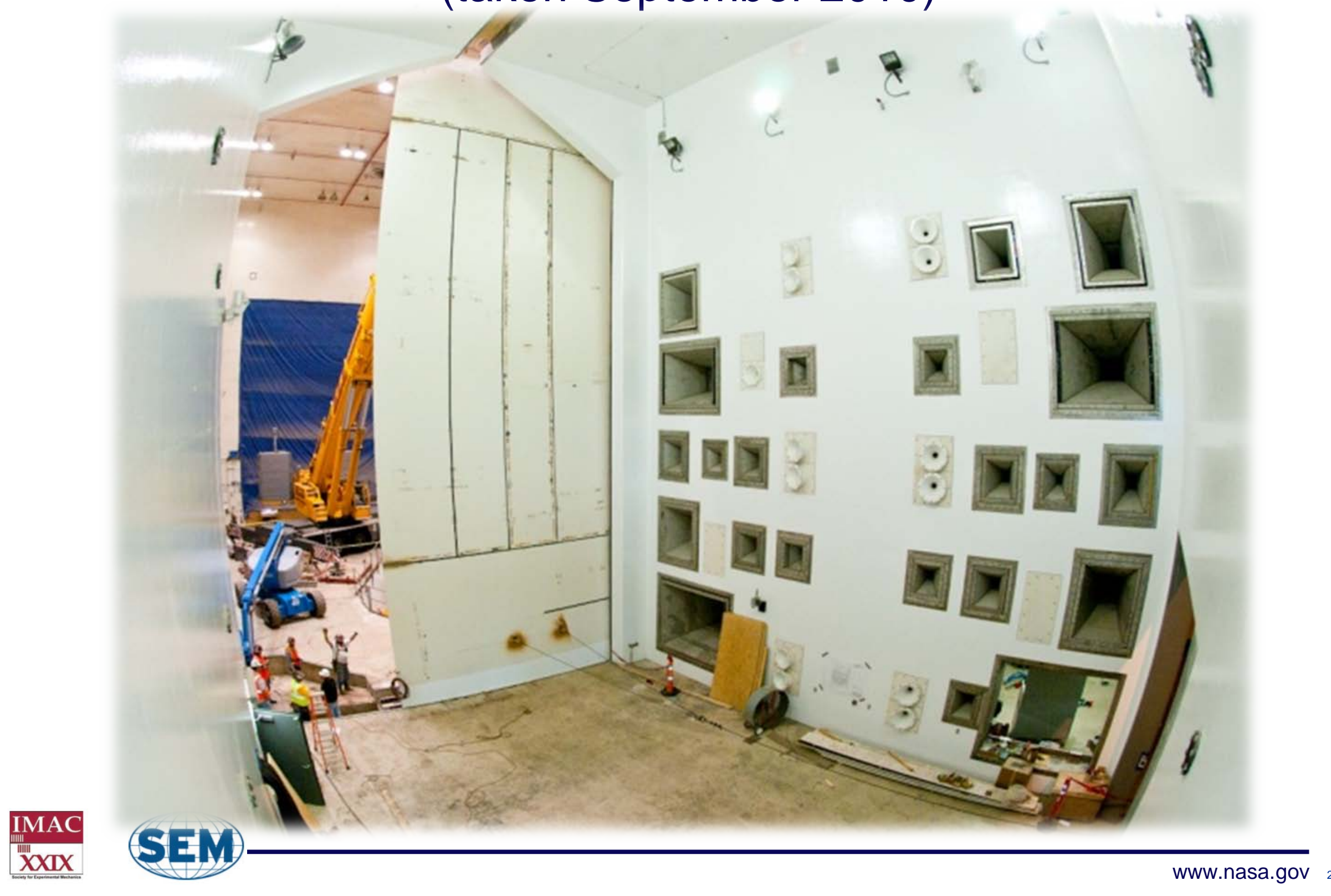


The authors would like to acknowledge the NASA SET Project Office for their continuing support and funding for the test programs discussed in this paper. The extensive contributions of the following organizations and individuals are particularly worthy of mention for their substantial role in this testing and the test data analysis effort:

- Benham Companies, LLC: Neil Waggoner, Josh Loehrke

- Aiolos Engineering Corporation: Ralph Leitner, Dr. Gary Elfstrom, Dr. Ramani Ramakrishnan, Alex Holzwarth, Sergio Raimondo

- TEAM Corporation: Bob Tauscher, Bill Woyski, Chon Mech

- Wyle Laboratories: Dr. Costa Glaretas, Chito Hermoso

- $\quad m+p$ International: Al Prosuk, Guido Bossaert

- Cambridge Collaborative Incorporated: Dr. Jerry Manning, Dr. Patricia Manning

- National Research Council: Dr. David Zimcik, Dr. Anant Grewal, Dr. Eric Chen, Viresh Wickramasinghe, Brent Lawrie, Luc Hurtubise

- Redstone Technical Test Center: Dr. Mike Hale

- Owens-Corning: Kevin Herreman, Don Hill 


\title{
Thank you
}

\section{Contact Information:}

\author{
William O. Hughes
}

NASA Glenn Research Center

William.O.Hughes@nasa.gov

\author{
Aron D. Hozman
}

NASA Plum Brook Station

Aron.D.Hozman@nasa.gov 